\section{Evento: da Proposta ao Planejamento}

\section{Marisa Canton ${ }^{1}$}

RESUMO: Aborda o perfil e enfoca a atuação do profissional de eventos na elaboração correta das propostas, com ênfase no uso adequado das estratégias de comunicação e marketing disponiveis no mercado para a otimização dos resultados e objetivos propostos.

PALAVRAS-CHAVE: Turismo e eventos: proposta; planejamento; estratégias; comunicação; marketing; negociação.

ABSTRACT: This paper presents a delineation of the event's profissional profile and analysis the importance of the right proposals. It emphazises the adequates strategies in communication and marketing that may be strategies in commiable in market.

KEY WORDS:Tourism and events: proposal; planning; communication; marketing.

\section{Evento - Conceito e Caracterização}

Falar em eventos sugere ao leigo, num primeiro momento, simplesmente algo festivo, encontros comemorativos e realizações de sucesso. Entretanto, no momento exato em que as mudanças na economia do mercado exigem novo modelo de empresa de comunicação, surge hoje um instrumento estratégico que trabalha totalmente integrado ao marketing de seus clientes e está comprometido com os resultados da empresa - o evento. Atividade esta que desponta como solução, nas mãos de profissionais criativos e competentes.

1. Bacharel em Turismo pela Faculdade Anhembi Morumbi. Mestre em Ciências da Comunicą̧ão pela Escola de Comunicaçōes e Artes da Universidade de São Paulo. Coordenadora Executiva do Centro de Capacitação de Docentes

End. para corresp : Av. Brig Faria Lima, 2287 - conj. 11 - Id Paulistano - 01452-000 - São Paulo - SP - Brasil.
Muito se tem falado sobre eventos, buscando esclarecer e justificar essa atividade exemplar que acompanha o indivíduo no decorrer de sua vida, fazendoo às vezes de público, consumidor e mesmo organizador. Há várias definições de evento, como as seguintes:

- conjunto de ações profissionais desenvolvidas com o objetivo de atingir resultados qualificados e quantificados junto ao público-alvo;

- conjunto de atividades profissionais desenvolvidas com o objetivo de alcançar o seu público-alvo através do lançamento de produtos, da apresentação de pessoas, empresas ou entidades, visando estabelecer o seu conceito ou recuperar sua imagem;

- realização de ato comemorativo, com ou sem finalidade mercadológica, visando apresentar, conquistar ou recuperar o seu público-alvo;

- ação profissional através de pesquisa, planejamento, organização, coordenação, controle e implantação de um projeto, visando atingir o seu público-alvo com medidas concretas e resultados projetados.

Na verdade, pode-se afirmar que evento é a soma de ações previamente planejadas com o objetivo de alcançar resultados definidos junto ao seu públicoalvo. Planejadas, porque o evento se realiza levando-se em consideração um fato ou acontecimento, as estratégias mercadológicas de acordo com os interesses e expectativas de um cliente ou promotor, e os objetivos a serem alcançados junto a determinado público. O evento, pelo próprio significado da palavra, é todo fato ou acontecimento, espontâneo ou organizado, que ocorre na sociedade; e do ponto de vista do profissional, pressupõe planejamento e organização. Esta proposta envolve a preocupação do organizador profissional de eventos em atender a todos os itens acima enunciados.

O evento, quando nas mãos do organizador profissional, passa a representar uma pequena empresa, dentro da empresa, com vida própria: arquivos, controles, sistema de operação e atendimento, justificando seu próprio planejamento, organização, direção e coordenação das tarefas. Assim, serão formadas várias células, tantas quantas forem o número de eventos propostos, e a empresa "mater" responsável passa a ser o organismo perfeito, que deverá manter o sistema equilibrado.

\section{Profissāo: Organizador de Eventos}

O mercado, em evolução constante para o Turismo de Negócios (os números da Embratur indicam crescimento de $13 \%$ para viagens de negócios entre 1989 e 1995 , enquanto as de lazer cairam 10\%), apresenta um perfil em que as empresas 
coligadas às empresas de propaganda e marketing investem na ação de eventos, como principal diferencial para oferecer soluções nas áreas de marketing, vendas, operação e assuntos corporativos. Cresce consideravelmente o campo profissional para o organizador de eventos, que não pode prescindir especialmente de conhecimentos técnicos, administrativos, de marketing e economia. É o comunicador do futuro, que já se faz presente.

Se, por um lado, o mercado de eventos teve aumento considerável, por outro, esse mercado tornou-se altamente competitivo. O profissional organizador de eventos deve exercitar continuadamente sua criatividade e inteligência, utilizando para a elaboração de suas propostas as mais atuais e modernas estratégias de comunicação e marketing disponiveis no mercado e adequadas àquele momento. Esse profissional deverá ter visão técnica de sua organização e visão global do momento de sua atuação, além de uma equipe de apoio coesa e eficiente, num organograma adequado - a pessoa certa no lugar certo.

Entre outras qualidades, o profissional de eventos deve ser seguro, gerando confiança para o cliente e funcionários; disciplinado, respeitando prazos, verbas e reuniões; ter flexibilidade, aceitando sugestões, adequando propostas, mudando etapas de trabalho; ter raciocínio rápido, entendendo a capacidade, anseios e expectativas dos clientes e funcionários; ter preparo fisico, disposição e saúde; ser realista, percebendo os limites, as opções e usá-las sabiamente; ter paciência infinita, exercendo o autocontrole e a serenidade.

Para os que já atuam no setor, essas colocações são óbvias e rotineiras. A essas qualidades pessoais, acrescentam-se as de atuação profissional:

- planejamento: estabelecimento de esquema orientador, relativo às ações futuras;

- organização: agrupamento lógico de tarefas;

- direção: tomada de decisões entre diversas alternativas; transmissão de ordens; chefia de subordinados e coordenação das atividades individuais;

- controle : verificação da execução do plano, a fim de corrigir os desvios e atingir os objetivos preestabelecidos.

Mas para atingir essas fases, passa-se por uma rotina de trabalho, às vezes de final não conclusivo para os prestadores de serviços do setor. O fato de se receber um convite para apresentação de uma proposta não confirma um contrato; mesmo assim, deve-se investir com criatividade e profissionalismo e lutar para obter bons resultados.

\section{Elaborando a Proposta de Evento}

Após a realização do "briefing" (diagnóstico) com o cliente ou promotor, parte-se para a elaboração e entrega da proposta, que não deverá ser propriamente o projeto detalhado, em que o planejamento terá destaque, com inclusão de cronogramas e orçamentos. A proposta, apoiada na pesquisa, deve ter local, data, estratégias, possíveis fornecedores e embasamento técnico, criativo e convincente, importantes instrumentos para a viabilidade e qualidade de um evento.

$E$, nesse momento, se faz mister a reflexão sobre a importância do uso da criatividade, visto que está diretamente ligada com o aspecto da organização. O simples fatode uma empresa decidir organizar um determinado evento, para atingir determinada meta, já demonstra o ato de criar uma forma de atingir seu objetivo. Considera-se ato criativo a simples escollha de um determinado tipo de evento e sua organização - aescolha de todos os meios que possibilitarão a realização do evento. Considerando-se um evento como o conjunto de atividades destinadas à otimização de ações profissionais em busca de resultados quantificados e qualificados junto ao público-alvo, deverá o organizador de eventos ser um profissional com suficiente sensibilidade para captar as alterações do mercado, a fim de atingir o objetivo almejado, ser capaz de levantar novas dúvidas, novas possibilidades, olhar velhos problemas sob novos ângulos, enfim ter imaginação criadora.

O processo criativo de um evento não significa uma brecha de originalidade, mas a busca de soluções de problemas objetivos, tais como:

- onde será realizado o evento?

- há um tema?

- que material será criado em função do tema?

- quem participará do evento?

- qual a duração?

- quais as atividades que ocorrerão no local?

- de quem será a responsabilidade de coordenação de cada atividade?

- qual o formato do evento e em que espaço será realizado?

- qual a verba disponível para o evento?

- o que será oferecido aos participantes em geral e aos convidados vips?

- qual a categoria de hotel e do transporte para o evento?

- quais os recursos necessários para a viabilização do evento?

As propostas devem ser originais, inovadoras, criativas e viáveis, na busca de soluções e respostas para todos os itens acima arrolados.

Considerando-se que o primeiro passo para a elaboração de uma proposta é a análise de pedido encaminhada pelo cliente, não se deve deixar de reiterar que 
essa proposta deverá perseguir a objetividade, atendendo às necessidades dos clientes. Se os objetivos não forem atendidos, a impressão inicial é de que a empresa e seus responsáveis não entenderam o que o cliente realmente desejava ou necessitava. As informações não foram transmitidas de forma adequada aos encarregados da elaboração da proposta. Cinco pontos fundamentais devem ser considerados na elaboração de uma proposta, são estes:

- demonstração de que houve claro entendimento do proposto;

- apresentação de um projeto razoável, fundamentado com lógica e persuasão;

- evidência de que o projeto funcionará;

- oferta de equipe qualificada para o desenvolvimento do projeto;

- estimativa razoável de custos e apresentada de forma clara.

Existem condições importantes paraaapresentaçãodeuna proposta, quais sejam

- o objetivo é submeter propostas que deve̊m ser entendidas, evitando-se que sejam mal-interpretadas pelos mais severos criticos;

- nunca se deve omitir informações importantes, assumindo que seus clientes já saibam. A omissão pode ser interpretada como falta de conhecimento do prestador de serviços;

- boas propostas não são vencedoras garantidas; no entanto, propostas ruins são perdedoras certas.

E, dentro desse contexto, pode-se colocar como principais funções de um administrador:

- organizar a proposta, de forma que possa ser rapidamente vista como resposta clara para todos os requisitos de uma solicitação;

- selecionar material relevante para o objetivo;

- editar o relatório com informações relevantes, em estilo harmonioso, de fácil entendimento e de formato uniforme.

As observações acima são apenas algumas sugestões para o preparo eficiente de encaminhamentos. Como cada evento e cada empresa/cliente possuem especificações técnicas e características peculiares, deve-seadaptar as informações do ramo em consideração. Sabe-se que não existe forma fixa e permanente de preparar propostas que vendam. No entanto, a criatividade dos administradores é fator de extrema relevância para o trabalho.

A análise de qual proposta deve ser aceita constitui uma das primeiras etapas do preparo de uma proposta. Ao se decidir por prepará-la, os administradores devem reunir-se e considerar as seguintes questões:

- tem-se capacidade de execução do traballo para todas as áreas?

- quantos e qual a quantidade dos concorrentes que se enfrentará nesse projeto?

- tem-se o quadro de funcionários disponivel e a capacidade financeira para atender o projeto?

- o cliente em perspectiva tem condições ou meios para obter fundos necessários e cumprir com o pagamento do projeto?

- tem-se condição de traballhar no projeto considerando sua localização geográfica?

Por outro lado, em caso de concorrência, antes de preparar um projeto, devese considerar os seguintes aspectos:

- qualidade e extensão do nivel de conhecimento de marketing para o desenvolvimento do projeto em questão;

- concorrência

- equipe que traballiará no projeto;

- experiência direta ou relacionada com o tipo de projeto e área geográfica;

- exigência para consultores, associados e subcontratações e suas prováveis disponibilidades;

- habilidade para atender todas as etapas do projeto;

- tempo suficiente, equipe e recursos financeiros para atender o projeto;

- habilidade de apresentar um projeto com condições de preços competitivos;

- interesse no projeto de forma geral.

A prestação de serviço propriamente dita inicia-se com o fechamento da proposta ou assinatura de um contrato. Nesse momento é que todas as promessas 
começam a ser cumpridas. Se as expectativas do cliente não forem atingidas, haverá insatisfação e perda de credibilidade.

Como em qualquer administração, isto implica quatro passos muito conhecidos, por mais desgastados que possam parecer:

- percepção: mostrar que o evento tem custos e que se trata de uma oportunidade que tem benefícios;

- avaliação: determinar qual a situação da empresa no momento, especialmente em comparação com o que é necessário fazer para se obter os resultados desejados;

- prestação de contas: estabelecer relatórios regulares; fornecer um plano financeiro acurado, com orçamentos razoáveis incluindo "cash flow" de pagamentos e projeções de receitas;

- ações: tomar decisões e fazer alocuções, estabelecendo rotinas e comunicações.

Adicionalmente, quanto às intenções do cliente, a exatidão das previsões apóia-se na qualidade do relacionamento com este. Em um bom relacionamento, 0 cliente partilha seus planos e expectativas com o organizador de eventos ou possibilita conhecer as suas intenções.

Para que a realização do evento ocorra com o mínimo de falhas necessita-se:

- quanto à empresa: qualificação técnica das equipes responsáveis pelas diferentes áreas: elaboração de planos, cronogramas e fluxogramas bem definidos; prática com alto grau de profissionalismo; controle de todo o processo: planejamento, organização, operacionalização e implementação;

- quanto ao produto em si : não perder a qualidade do produto em todas as suas fases; buscar sempre atingir os objetivos do planejamento; atender às expectativas dos objetivos dos vários públicos; adequá-lo sempre às necessidades emergentes;

- quanto ao preço: estar condizente com a realidade do mercado; considerar sempre qualidade $\mathrm{x}$ preço e, especialmente no caso dos patrocinadores, a relação custo $x$ benefício;

- quanto à distribuição e venda: comerciar em canais de fácil acesso ao público; estabelecer formas adequadas e viáveis de pagamento; implantar sistemas de controle contábil e financeiro eficientes; otimizar a verba disponível;

- quanto à comunicação: elaborar plano de comunicação eficiente e compactuado ao mercadológico, através de campanhas de grande impacto, mensagens objetivas, planejamento da divulgação (mídia e assessoria de imprensa), produção de peças criativas que desperte e estimule a participação do público;
- quanto ao apoio e recursos: estabelecer formas adequadas de negociação, formas de apoio e obtenção de recursos. A negociação perfeita é aquela que leva em conta não apenas o que está sendo negociado, mas também a forma.pela qual se está negociando. E necessário ouvir a todos, sendo esta a oportunidade para que todas as partes manifestem os seus objetivos e propostas.

O patrocinador em potencial precisa de um plano absolutamente positivo e para isto é importante que o projeto proponha com exatidão as vantagens que o empresário terá, caso participe do empreendimento. Evento é um processo de venda comercial ou institucional. No caso institucional, o evento possibilita a fixação da imagem do cliente (patrocinador). Se o evento vier a utilizar a mídia, o cliente (patrocinador) passa também a ser anunciante.

O marketing institucional transmite a idéia de associar a empresa a um evento vencedor, existindo a correlação direta e recíproca entre a qualidade do evento e o prestígio de quem o patrocina.

A empresa quando concede seu aval de participação a um evento, transmite simpatia com o mesmo, viabilizando e apostando no sucesso do projeto.

Com o fito de auxiliar o empresário a decidir em relação a sua participação ou não em um evento, é muito importante dispor de informações seguras, sempre frisando os objetivos de participação de forma bastante precisa, mensurável e compativel, tendo em vista que a relação custo-benefício seja a maximização do retorno esperado.

Ao demonstrar o projeto ao patrocinador, é importante trabalhar com a emoção do patrocinador, personalizando a apresentação do "layout" e das peças promocionais com o logotipo da empresa. Esse fato irá contribuir para que o empresário visualize sua empresa como colaboradora do evento.

O profissional organizador de eventos deve ser flexível, criativo e incorporar-se realmente ao projeto, sempre se referindo a este no presente e nunca no condicional.

Tem-se como empresa organizadora um tipo de organização empresarial, especializada no planejamento, organização e implementação de eventos, cuja atuação se caracteriza de duas formas:

- através dodesenvolvimento de eventos(produtos) próprios e comercializando-os no mercado;

- planejando, organizando, implementando ou comercializando eventos para terceiros, por solicitação ou encomenda.

Em ambas as formas a empresa deverá possuir estrutura própria para desenvolver todas as etapas, ou parte delas, como também contratar fornecedores específicos para cada atividade, dentro do contexto necessário para a viabilização adequada do evento.

Tendo em vista esse princípio, outros enfoques fazem-se necessários estudar: 
- em relação ao público: o evento será considerado aberto, fechado ou misto;

- do ponto de vista do mercado: qual a abrangência geográfica e demográfica referente a públicos: próprio (do evento) e de terceiros (empresas em geral, sindicatos, associações e outros);

- quanto aos objetivos da proposta: comercial (patrocinadores, apoios, participantes comerciais); de interesses generalizados (participantes, compradores, fornecedores, transportadoras, agências);

- quanto à abrangência: público próprio (do evento) e de terceiros (empresas em geral, sindicatos, associações e outros)

Uma empresa que deseja perenizar e crescer no mercado em que atua deverá ter seus objetivos e missão claros, o que irá permitir o conhecimento de onde quer chegar e as estratégias e planejamento necessários para se atingir esses objetivos. Terá que definir qual será sua imagem no mercado. Será uma empresa especializada (aquela que busca excelência dentro da oferta de serviço específico), ou inovadora, ou mesmo aquela que busca a internacionalização?

A busca diferenciada dos serviços, com base nos benefícios que esses possam proporcionar aos vários segmentos de clientes, é uma forma de se obter vantagens em relação à concorrência.

O comportamento estratégico é um caminho seguro, para que se obtenha vantagens competitivas ao longo do tempo, pois este estará sempre buscando minimizar as ameaças ambientais e maximizar as oportunidades do mercado.

A empresa que tiver o planejamento estratégico como um dos seus grandes instrumentos de mercadologia e de comunicação, terá o seu "lugar assegurado", pois sabe-se que o planejamento estratégico forma condições para a tomada de decisões, criando barreiras competitivas duráveis em relação ao ambiente empresarial em que o negócio se insere.

Para que um evento tenha sucesso no mercado, na sua viabilidade total como investimento eficiente, seja qual for o seu tipo, segmento ou categoria, é necessária a combinação de uma série de fatores ou variáveis(condicionantes) de comunicação e mercadológicas, que estarão em sintonia e perfeitamente otimizados, levando-se em consideração os dados de mercado para posterior análise, determinação dos objetivos e estratégias e execução dos planos de ação. Resumindo os itens importantes referentes a modos de comunicação, quando da necessidade de obter investimentos para algum evento, têm-se os seguintes:

- forneça breve história de seu produto/serviço, o que faz e para que serve;

- forneça um resumo objetivo de tarefa que se deseja realizar. A tarefa é original, diferente, inovadora, criativa e viável:
- por que o projeto é necessário?

- que necessidade o produto/serviço está procurando preencher?

- como a tarefa será realizada e a quem servirá?

- por que o produto/serviço é a instituição certa para levar adiante o projeto?

- o momento é certo para isso?

- forneça um plano financeiro acurado e com orçamentos razoáveis, incluindo projeções de receitas, periodo de apoio futuro de um calendário para completar o projeto proposto.

\section{Estratégias de Comunicaçào para Eventos}

Taticamente o evento é um processo de venda comercial ou institucional e a sua comunicação constitui-se no principal objetivo de sua existência. Deve-se ter como meta a definição das mensagens e dos meios de comunicação, através dos quais será inforınado e motivado o público-alvo.

O público varia de evento para evento, mas pode-se enumerar os principais segmentos de público:

- congressistas ou convencionais;

- expositores;

- colaboradores especiais;

- autoridades;

- imprensa;

- público em geral.

Para cada segmento há que ser analisada e elaborada a estratégia de comunicação adequada. Como regra geral, a melhor opção a ser adotada pela empresa é aquela que traz como resultado o mais baixo custo por produto vendido ou por clientepotencial atingido. Freqüentemente a opção ideal é aquela que reserva várias ferramentas da comunicaçãodirigida, criando um sinergismo em que a soma das partes e maior que o todo.

Os meios de comunicação devem estar em consonância com a natureza das mensagens e as caracteristicas do público-alvo. Pode-se enumerar os seguintes meios de comunicação: 
- jornais, revistas, rádio e televisão - comunicação de massa, mas de utilização bastante cuidadosa:

- cartazes informativos e molivacionais são uma das formas mais utilizadas de divulgação de congressos (não confundir propaganda com divulgação);

- mala direta, para informar e motivar diretamente o público de interesse já identificado, através de folhetos, cartas especiais e até amostras de produto funcionando como "teasers".

Todas as mensagens, qualquer que seja o meio utilizado, devem manter a relação de harmonia. A adoção de um determinado meio de comunicação nãoé fato excludente da utilização de outras formas de comunicação. Ao contrário, o mais interessante é, em geral, a adoção planejada, simultânea ou sucessivamente, de dois ou mais meios de comunicação.

Um evento pode comunicar um aspecto cultural, um produto, uma informação, uma ideologia. Alguns aspectos são positivos:

- aproxima o público do produto/empresa/marca;

- associa a marca, ou nome, ao evento ou atividade;

- cria imagem favorável junto à opinião pública;

- reduz barreiras existentes

- amplia o nível de conhecimento da marca;

- abrange maior número de público direcionado.

Alguns pontos negativos, a saber:

- necessidade de outros meios como reforço;

- necessidade de continuidade para sentir o efeito desejado;

- riscos de ocorrências negativas que se associem à marca;

- riscos de falhas na organização;

- riscos em relação à divulgação do evento.
Do ponto de vista mercadológico, o evento, além de representar excelente meio, instrumento ou estratégia de marketing para a empresa que o queira explorar, é considerado um produto, quando organizado (montado) por empresa ou institui ção, quer com objetivos comerciais quer instituicionais, porém sempre visando atender a necessidade do mercado e público a quem se destina. $\mathrm{E}$, nesse contexto, o evento passa a representar um produto para a empresa, de acordo com as várias facetas:

- quando representa a sua própria atividade comercial de cujos resultados a empresa depende para sobreviver e crescer no mercado. São eventos realizados pelas inúmeras empresas organizadoras que existem no mercado;

- como subproduto, ou seja, serve de apoio para comercializar ou divulgar os seus principais produtos ou para atingir objetivos mercadológicos, que podem ser externos ou internos;

- quando os hotéis se utilizam da realização de eventos internos como uma das formas de garantir hospedagem, freqüência nos restaurantes, boates e outros;

- como forma de angariar fundos, difundir atividades sociais, conhecimentos científicos e outros;

- como forma institucional: criando ou mantendo imagem positiva da empresa junto à vários públicos

Entende-se como produto todo o bem material ou imaterial (serviço) que é capaz de atender a necessidade, seja primária, secundária ou psicológica. Fica claro, no entanto, que o produto somente deverá existir quando satisfazer a necessidade de um determinado público, em um determinado mercado.

\section{Consideraçōes Finais}

Osucessode qualquer empresa seinicia com o serviço ou produto. Raramente algumna ferramenta de marketing consegue transformar um mau produtokserviço em sucesso de venda. Portanto, o sucesso de marketing se inicia quando o serviço/produto tem qualidade compatível com o público-alvo a que se destina.

Nenhum negócio será duradouro se a empresa não levar em conta a necessidade de adaptar o seu serviço às transições, expectativas e necessidades de seus clientes. Implica também definir, com clareza, quais os mercados e segmentos que a empresa pretende operar a curto, médio e longo prazos, com que tecnologia, qual a amplitude dos serviços que poderá oferecer ao mercado reconhecer suas limitações, sua competência e suas vantagens em relação à concorrência. 
É de suma importância estabelecer os cronogramas e fluxogramas, para que a participação possa atingir bons resultados.

Deve-se sempre planejar o trabalho e depois trabalhar o projeto, pois assim com certa antecedência pode-se antecipar emergências para cada caso.

Não existe bom evento sem a participação da mídia, principalmente a eletrônica, mais uma vantagem que o patrocinador irá absorver.

Em função de todas as vantagens concedidas ao futuro patrocinador, é o momento de apresentar o custo do patrocínio que, em contrapartida com uma série de beneficios, se torna convidativo.

E, finalmente, pode-se avaliar a participação em eventos através de algumas observações e resultados:

- impacto;

- concentração de público;

- imagem positiva associada à marca;

- efeito residual de comunicação, através de notícias nos meios e veículos de comunicação;

- volume de verba condizente com o retorno esperado;

- qualidade na organização e implementação pelo plano de divulgação - mídia e assessoria de imprensa, levantamento de opiniões, tabulação e análise.

\section{Referências Bibliográficas}

OLIVEIRA, Dijalma de Pinho Rebouças de. 1994. Planejamento estratégico: conceitos, metodologia e práticas. Atlas. São Paulo.

KOTLER, Philip. 1980. Marketing. Allas. São Paulo.

NUNES, Marina Martinez. 199ó. Cerimonial para executivos: um guia para execução e supervisão de eventos empresariais. Sagra-D C. Luzzallo. Porto Alegre

MUYLAERT, Roberto. 1993. Marketing cultural \& comunicação dirigida. Globo . 